\title{
THE USEGE OF MACHINE VISION IN HOT STRIP ROLLING PROCESSES
}

\author{
Martin MENŠíK, Hana ŠPAČKOVÁ, Jaroslav SLÁČALA, Jan BŘEZINA
}

VSB - Technical University of Ostrava, Ostrava, Czech Republic, EU, martin.mensik.st@vsb.cz

https://doi.org/10.37904/metal.2019.783

\begin{abstract}
Metallurgy is one of the most complex industries. It integrates the experiences that our ancestors have moved for generations to better understand chemical and manufacturing processes. Over the past few decades, metallurgy has experienced a massive transformation. Minimizing ecological burdens, maximizing economic indicators and, last but not least, lacking skilled human resources puts the future of metallurgical process management in a difficult task of replacing human power in heavy and dangerous operations while improving technological processes. The way to achieve this goal is to give the processing technology a new dimension based on the experience and knowledge of experts. Machine vision is one way to achieve this goal.
\end{abstract}

Keywords: Metallurgical production, machine vision, laser, hot strip mill, rolling mill, control, automation

\section{INTRODUCTION}

Rolling the material is one of the basic methods of producing the final product. In this way, for example, wires, rails, building materials, etc. are produced. In the case of long materials, the hot rolling method of the reverse mill is used. This method is also used for special profiles for structural purposes. The hot rolling process is based on preheating the material to the desired temperature, which is about $120{ }^{\circ} \mathrm{C}$. At this temperature, maximum elasticity is achieved. The aim is to achieve the desired shape and length and minimize internal stress. From the heating furnace, the material is descaled, which is formed during heating and is conveyed on the roller conveyor to the rolling mill. The reverse rolling mill consists of a set of cylinders and inlets, and the material passes through each of the inlets back and forth. At each inlet there is a gradual deformation up to the desired final shape. Two different constructions are used to guide each input.

- $\quad$ Rigid rolling stand

- Moving rolling stand

In the case of a fixed rolling mill, the manipulator, or rulers, are routed to the correct inputs depending on the rolling recipe. The material always moves over the entire width of the conveyor. If the material needs to be rotated during rolling, a manipulator is used. Compared to the previous method, rolling mill rolling is based on the, fact that the material is always positioned at the center of the conveyor and moves the rolling mill according to the rolling recipe. The rolling speed is dynamic and ranges from 0 to $3 \mathrm{~m} / \mathrm{s}$. The pressures that affect the material when deformed are up to $10 \mathrm{MN}$. Drive train torque is up to $750 \mathrm{kNm}$. It is $375 \mathrm{kNm} / \mathrm{roll}$. An essential part of such a process is the lubrication of the rolling mill and its cooling. Due to the lubrication of the material, cooling of the rolling mill and manipulators, steam is produced which contains lubricant and metal material. Special lubricants and graphite are used for lubrication. Another section of the rolling process is to cool the material and divide it to the desired length. In some cases, a reheating furnace is also included to relieve internal stress.

\section{DESCRIPTON OF THE ISSUES}

During the rolling process, the material changes its dimensions. Especially length and cross section. For profiles that are symmetrical or axially symmetrical, there is no uneven deformation during the rolling process and there is no asymmetric stress in the material that could cause curvature. In the case of special profiles that are not axially symmetrical, the pressure of the rollers on the material is uneven and stress is generated 
in the material. Material distortion and curvature occurs. If the material passes through the rolling mill back and forth during one cycle and does not rotate about its longitudinal axis by $90^{\circ}$, there is no problem with the entry guidance. If the material is rotated by $90^{\circ}$ during the rolling process, there is a problem of directing the curved material to the correct inlet.

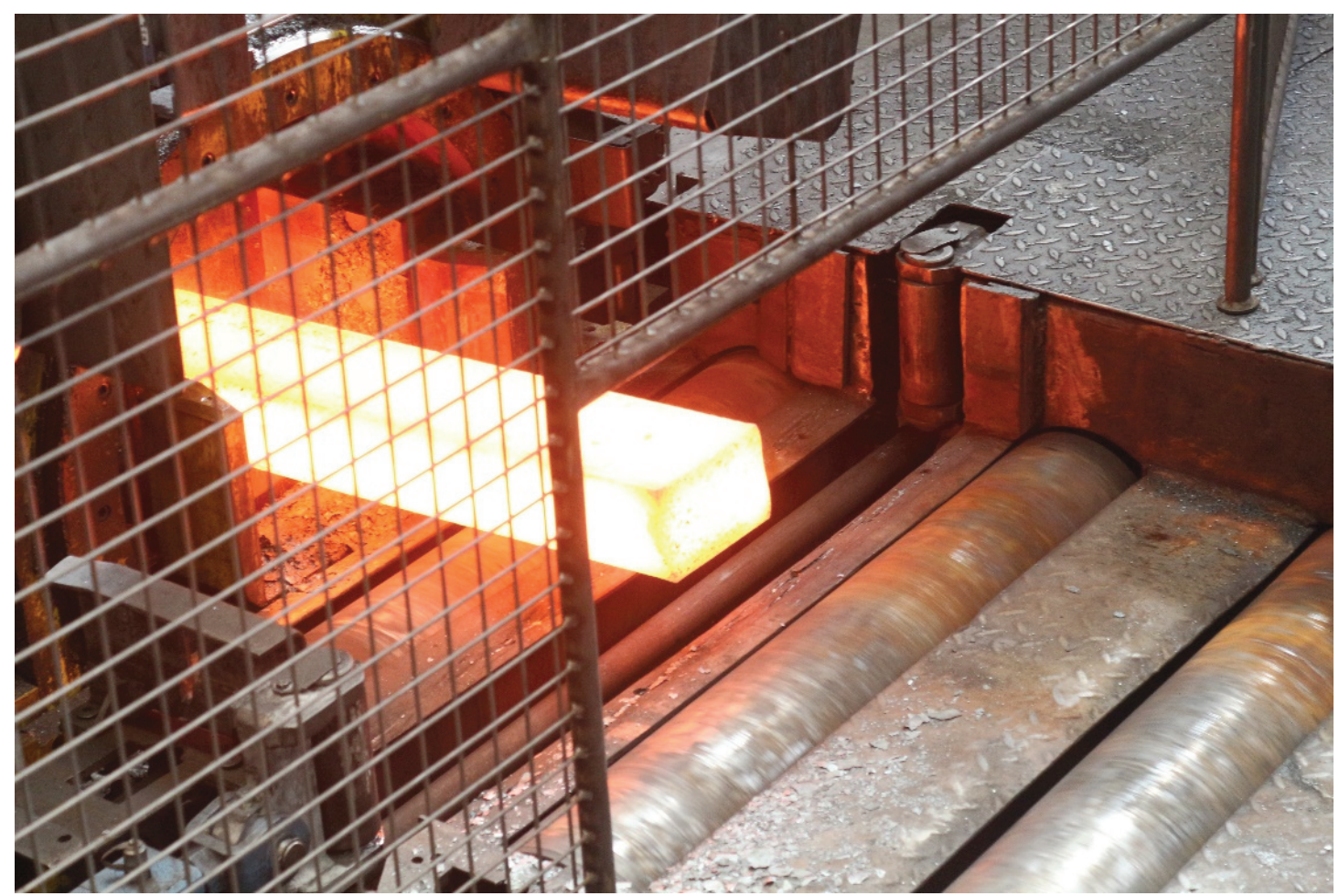

Figure 1 Rolling material and partly visible round manipulator

If the material (Figure 1.) hits the edge of the inlet or it may get stuck, the rolling device or manipulator may be damaged. The requirement is to avoid such situations for the smoothness of the rolling process. The average time of one recipe is about 5 minutes. Depending on the number of cycles and the complexity of the shape and length of the final product. Time is crucial to maintain the desired temperature during the rolling process. The disproportionate extension of rolling time could cause excessive surface cooling and this temperature inhomogeneity causes stress within the material. This can cause surface and internal defects

\section{POSSIBLE SOLUTIONS}

There are several solutions to avoid these problems. One of the options is to change the technological process and design of the rolling mill. Extending the rolling stand with guide rollers in the vertical and horizontal directions with proportional pressure control would be ideal, but very expensive. In most cases it is impossible to implement because of the need to change the design of the whole plant. Another option is to adjust the downforce and avoid curvature. However, this variant requires a change in the radius of the top and bottom rollers to distribute the pressures within the material evenly. In this case, we have to go back to the very beginning of the cylinder design preparation for the individual profiles. To do this, it would be necessary to create a model environment where would be counted with uneven stress depending on the shape of the profile and the individual cuts. At present, there are considerable differences in the preparation and design of cylinders. This is one of the possible topics that can be developed. Another option that can be used to solve this problem is machine vision. In this case, it is no longer a change of design or a change in the technological process, but it is about adding an additional source of information to the control system. 


\section{MACHINE VISION}

The goal of machine vision deployment is to identify material in space. The rolling process has its specifics, which must be counted in when designing the solution. High temperatures, dust, graphite fog, steam. Together with the changing light conditions, it's a very difficult task. It is necessary to choose a solution that would survive under these conditions. It must be robust with minimum maintenance and work with the required accuracy and reliability. For the classical concept of machine vision, the basic condition must be fulfilled. Constant lighting conditions. This cannot be achieved in a rolling environment. During lubrication and cooling, there is a vapor that contains lubricant. Therefore, it is necessary to choose a structural solution that will be affected by these influences. It is not possible to optimize lighting conditions, but it is possible to optimize scanning methods. The use of sensors that operate in the infrared spectrum is very expensive and due to the radiation of the heat it is not possible to achieve the required accuracy. Another factor that negatively affects the possibility of using infrared sensors is steam, which would introduce additional errors into the identification process. The material heated to $1150^{\circ} \mathrm{C}$ has a color that is very visible in the gray rolling mill environment. This is a wavelength of about 600 to $620 \mathrm{~nm}$. (Figure 2). This can be used for solution. By a suitable sensing method, the correct lens and the use of lasers, it is possible to reliably identify the material in space based on the color spectrum decomposition. After the subsequent image processing, it is possible to work with the data and use it in the control process.

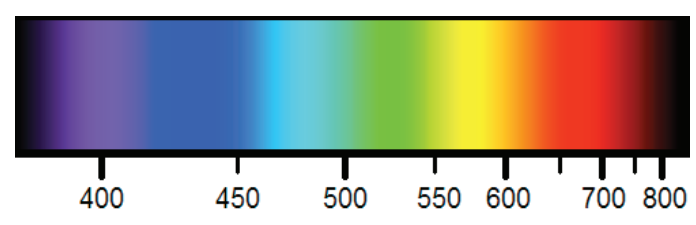

Figure 2 Wavelengths of the color spectrum

\section{MACHINE VISION SOLUTIONS IN A HOT STRIP MILLING PROCESS USING A LASER}

The method we propose to use to solve this problem is based on image analysis. The rolling process speed for long products can be up to $3 \mathrm{~m} / \mathrm{s}$. By using a conventional camera and taking 10 frames per second, we can get a lot of usefull data. Depending on the design, the distance of the guidance system from the inlets of the rolling stand may be between $0.5 \mathrm{~m}$ and $2 \mathrm{~m}$. This is enough time to process and evaluate the acquired data from gathered images. The future solution will consist of two parts, HW and SW. The HW part is based on a camera system and an external computing unit. The external computing system was chosen for its independence from commercial camera systems. It is necessary to solve the issue of environmental influences in the CCTV system. Cooling mist, graphite dust, unstable light conditions. Due to the high temperatures, the camera is stored in a chilled box and the outer window must be equipped with a permanent air flow. This airflow prevents contamination of the external optics. An important element is the right optics, which must work with sufficient depth of field, depending on its location and the required accuracy. The influence of steam and its impermeability will be eliminated by the shutter speed and the polarizing filter. Here is necessary to find the right combination so that we do not deprive the details of an unsuitable polarizing filter. Individual edges of the device may be difficult to identify under unstable light conditions. A laser will be used as the identifier. In connection with the next procedure, a red laser was chosen. By combining several lasers of appropriate beam intensity and width, a raster will be created with checkpoints to make subsequent data processing. The whole process is based on image decomposition into individual color spectra and their subsequent filtration. The rolled material is preheated to about $1150^{\circ} \mathrm{C}$. and its wavelength is between 600 and $630 \mathrm{~nm}$. Like a red laser. By decomposing the image into RGB folders and setting filters for red color only, we convert the image from the color spectrum to the monochrome spectrum. [6] Further filtering with detail to the wavelength between 600 and $620 \mathrm{~nm}$, which interests us to get the necessary data. These data are then binarized and stored in a matrix for subsequent analysis. This raw data serves as a source for subsequent mathematical analysis. 


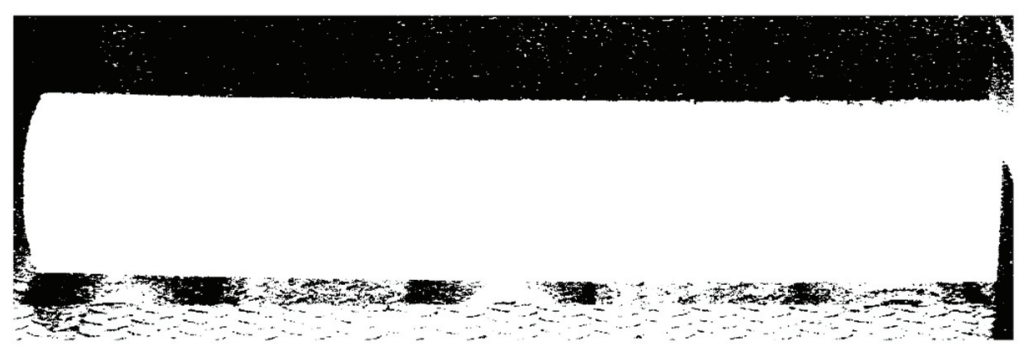

Figure 3 Mathematical algorithms help to identify edges of rolling material in gathered images

The processing method (Figure 3) will be based on simple algorithms to achieve the desired speed and the system is stable and robust. Under laboratory conditions, MATLAB and its image processing library were used. The goal of this process is to define the inlet and material coordinates. These data can be used to control the technological process, visualization, or as a source of preventive shutdown of the material shift if the curvature rate could cause damage to the rolling stand or manipulator.

\section{CONCLUSION}

The useage of machine vision and laser in heavy industry environments to identify objects gives new control dimensions. The deployment of vision-based technologies enables you to work in inaccessible spaces and human-hazardous conditions. The data obtained by this technology can be used as a source of input for expert systems. These technologies will make it safer and more efficient to work. Another important fact is that in the field of metallurgy in recent years we have encountered the issue of the outflow of specialists and the absence of generational change. Utilizing the expertise of metallurgical process specialists and implementing this experience in expert systems knowledge bases is one way to eliminate this shortage of skilled and experienced experts.

\section{ACKNOWLEDGEMENTS}

The work was supported by the specific university research of Ministry of Education, Youth and Sports of the Czech Republic No. SP2019/17 and SP2019/62

\section{REFERENCES}

[1] POHLUDKA, M., ŠTVERKOVÁ, H., ŚLUSARCZYK, B. Implementation and Unification of the ERP System in a Global Company as a Strategic Decision for Sustainable Entrepreneurship. MDPI. 2018. vol. 10, issue 8, no. 2916.

[2] KONVICKA, D., VITALIEVICH, S. V. New generation APS systems for demanding planning environments. In: International May Conference on Strategic Management. 2018. pp. 60-69.

[3] SEIDL, D., KOŠTIAL, P., JANČíKOVÁ, Z., RUŽIAK, I., RUSNÁKOVÁ, S., FARKAŠOVÁ, M. Modal analysis Measurements versus FEM and artificial neural networks simulation, Communications in Computer and Information Science. 2011. vol. 188 CCIS, Issue PART 1, pp. 170-175.

[4] DAVID, J., VROZINA, M. AND H. NOVAKOVA. Control of dependability of metallurgical processes such as logistics chains. In: METAL 2012: 21st International Conference on Metallurgy and Materials. Ostrava: TANGER, 2012, pp. 1702-1708.

[5] GARZINOVA, R., SVEC, P. and R. FRISCHER. Operative control with structured data processes in steel operations environment. In: METAL 2014: 23rd International Conference on Metallurgy and Materials. Ostrava: TANGER, 2014, pp. 1647-1653.

[6] DOBEŠ, M., MACHALA, L., TICHAVSKÝ, P., POSPIŠIL, J., HumanEyeRecognition Using the Mutual Information. Optik Volume 115, No.9, p.3099-405, Elsevier 2004 